\title{
RENTABILIDADE ECONÔMICA DO MARACUJAZEIRO-AMARELO PLANTADO EM COVAS E EM PLANTIO DIRETO SOB MANEJO ORGÂNICO ${ }^{1}$
}

\author{
SEBASTIÃOELVIRO DEARAÚJO NETO², REGINALÚCIAFÉLIX FERREIRA \\ FREDERICO SILVATHÉ PONTES ${ }^{4}$, JACSON RONDINELLIDA SILVANEGREIROS
}

RESUMO - O objetivo deste trabalho foi avaliar a rentabilidade econômica do maracujazeiro-amarelo plantado em covas e em plantio direto sob manejo orgânico no Acre. Avaliaram-se cinco tipos de preparo do solo: $\mathrm{T}_{1}$ - plantio direto com cova do tamanho do torrão $(0,19 \mathrm{~m}$ x $0,063 \mathrm{~m})$, com adubação em cobertura; $\mathrm{T}_{2}$ - cova de 0,30 × 0,30 × $0,30 \mathrm{~m}$, com adubação de plantio na cova; $\mathrm{T}_{3}$ - Idem $\mathrm{T}_{2}$, com adubação em cobertura; $\mathrm{T}_{4}$ - cova de $0,50 \times 0,50 \times 0,50 \mathrm{~m}$, com adubação de plantio na cova, e $\mathrm{T}_{5}$ - Idem $_{4}$, com adubação em cobertura. Os custos econômicos e operacionais médios foram maiores para os sistemas com plantio em covas de 0,50 m, por apresentarem elevado custo total de produção e menor produtividade. A receita líquida foi maior nos sistemas de preparo com covas de $0,30 \mathrm{~m}$, com adubação na cova ( $\mathrm{R} \$ 10.234,19 / \mathrm{ha})$ e em cobertura $(\mathrm{R} \$ 11.501,44 / \mathrm{ha})$ - e no plantio direto ( $\mathrm{R} \$ 8.925,08 / \mathrm{ha})$. Em todos os tratamentos, a situação econômica foi de lucro supernormal, assim a tendência é de mais agricultores entrarem na atividade.

Termos para indexação: Passiflora edulis f. flavicarpa, Agroecologia, análise financeira.

\section{ECONOMICAL RENTABILITY OF THE YELLOW PASSION FRUIT TREE PLANTED IN HOLES AND IN NO-TILLAGE UNDER ORGANIC CULTIVATION}

\begin{abstract}
The objective of this research was to evaluate the economical profitability of the yellow passion fruit tree planted in hole and no-tillage under organic cultivation in the state of Acre, Brazil. It was evaluated five types of preparation of the soil: $\mathrm{T}_{1}-\mathrm{No}_{\mathrm{O}}$ tillage with a hole of the size of a clod $(0.19 \mathrm{~m} \times 0.063 \mathrm{~m})$ with covering; $\mathrm{T}_{2}$ - hole of $0.30 \mathrm{~m} \mathrm{x} 0.30 \mathrm{~m}$ x $0.30 \mathrm{~m}$ with fertilization in the hole of planting; $\mathrm{T}_{3}$ - similar to $\mathrm{T}_{2}$ but with fertilization of coverage; $\mathrm{T}_{4}$ - hole of $0.50 \mathrm{~m} \times 0.50 \mathrm{~m} \mathrm{x} 0.50 \mathrm{~m}$ with fertilization in the hole of planting; and $\mathrm{T}_{5}$ - similar to $\mathrm{T}_{4}$ but with fertilization of coverage. The economical and operational costs medium were larger for the no-tillage and the planting systems in holes of $0.50 \mathrm{~m}$, they present an elevated total cost of production and smaller yield. The liquid revenue was larger in the planting systems with holes of $0.30 \mathrm{~m}$ with fertilization in the hole $(\mathrm{R} \$ 10,234.19 / \mathrm{ha})$ and of coverage $(\mathrm{R} \$ 11,501.44 / \mathrm{ha})$ and in the no-tillage system $(\mathrm{R} \$ 8,925.08 / \mathrm{ha})$. In all of the treatments, the economical situation was of supernormal profit, so the tendency is of more farmers to enter in the market.
\end{abstract}

Index terms: Passiflora edulis f. flavicarpa, Agroecology, Financial analysis.

\section{INTRODUÇÃO}

A produção de maracujá passa por forte retração causada pela concorrência do suco produzido no Equador, principal concorrente brasileiro. Nos últimos anos, o baixo preço internacional do suco levou as indústrias a pagarem menos aos agricultores, que passaram a investir cada vez menos nos pomares até o abandono da atividade, ocasionando forte queda da oferta de maracujá para indústria (Meirelles, 2006). Aliado aos preços baixos, os custos elevados, principalmente em cultivo convencional, podem proporcionar situação de resíduo, pois a receita pode ser menor que os custos, por isso as práticas de manejo adotadas são fundamentais para o sucesso na produção (Araújo Neto, 2004).

Um aspecto negativo no negócio do maracujá é o endurecimento dos frutos, uma das doenças mais importantes da cultura do maracujazeiro no Brasil, encontrada nas principais regiões produtoras (São Paulo, Minas Gerais, Rio de Janeiro, Espírito Santo, Bahia, Pernambuco e Pará, além do Distrito
Federal). Plantas infetadas apresentam mosaico e frutos com endurecimento do pericarpo, e grande redução da polpa. Essa enfermidade é causada por diversos isolados de potyvírus, previamente classificados como PWV, e também constituem uma estirpe do CABMV (Nascimento et al., 2004).

Além da sustentabilidade ambiental, a agricultura orgânica abrange também as dimensões sociais e econômicas da sustentabilidade. Esse intuito implica a busca por menores custos de produção, maior geração de emprego e diminuição das externalidades negativas, entendidas como os custos da degradação ambiental e a contaminação humana por uso de agrotóxicos e alimentos contaminados, excluídos do cálculo econômico na atividade produtiva (Cavalcanti, 2004).

O preparo do solo (coveamento) para o plantio do maracujazeiro é um dos fatores que oneram o custo de implantação, exigem mão-de-obra e podem desestruturar o solo; mesmo assim, a literatura atual recomenda covas variando de $0,30 \times 0,30 \times 0,30$ a $0,50 \times 0,50 \times 0,50 \mathrm{~m}$, inclusive em sistema

\footnotetext{
1( Trabalho 004-08). Recebido em: 05-12-2007. Aceito para publicação em: 28-08-2008.

${ }^{2}$ Eng $^{\circ}$. Agr ${ }^{\circ}$. Dr. Fitotecnia. Professor da Universidade Federal do Acre. BR364, km04, CEP 69.915-900, Rio Branco, Acre. Telefone(68)3901-2670. email: selviro2000@yahoo.com.br;

${ }^{3}$ Eng $^{\mathrm{a}}$. Agr ${ }^{\mathrm{a}}$. Dr ${ }^{\mathrm{a}}$. Fitotecnia. Bolsista PRODOC/CAPES/UFAC. (68)3901-2670 e-mail: reginalff@yahoo.com.br

${ }^{4}$ Eng $^{\circ}$. Agr ${ }^{\circ}$. Dr. Economia Rural. Prof ${ }^{\circ}$. Universidade Federal Rural do Semi-Árido. Caixa Postal 137, CEP 59.625-000, Mossoró - Rio Grande do Norte. e-mail:frederico@ufersa.edu.br

${ }^{5} \mathrm{Eng}^{\circ}$. Agr ${ }^{\circ}$. Dr. Genética e Melhoramento Vegetal, Pesquisador da Embrapa, Acre. (68) 3212-3200. jacson@cpafac.embrapa.br
} 
orgânico (Silva \& Oliveira, 2001; Penteado, 2004). Simão (1971) afirma que o limite do tamanho da cova deve ser estabelecido por critérios econômicos, preferindo-se as maiores covas.

A agricultura orgânica tende a ser economicamente eficiente pelo baixo uso de insumos externos e manutenção de produtividades constantes. Na horticultura orgânica, por exemplo, o custo de produção é aproximadamente $25 \%$ menor que no sistema convencional de produção de hortaliças (Souza, 2005).

O objetivo deste trabalho foi analisar a rentabilidade econômica da produção de maracujazeiro-amarelo plantado em covas e em plantio direto sob manejo orgânico no Acre.

\section{MATERIAL E MÉTODOS}

O experimento foi conduzido na Universidade Federal do Acre - UFAC, situada em Rio Branco, Acre, entre a latitude de $9^{\circ}$ $25^{\prime}$ e $10^{\circ} 30^{\prime} \mathrm{S}$ e longitude entre $67^{\circ} 00^{\prime}$ e $67^{\circ} 50^{\prime} \mathrm{W}$, a uma altitude de $150 \mathrm{~m}$.

O delineamento experimental adotado foi o de blocos casualizados, com 5 tratamentos e 4 repetições, com 4 plantas por parcela. Os tratamentos corresponderam a: $\mathrm{T}_{1}-$ Plantio direto (cova do tamanho do torrão, medindo $0,19 \mathrm{~m}$ x 0,063 m, e adubação em cobertura); $\mathrm{T}_{2}$-cova de $0,30 \times 0,30 \times 0,30 \mathrm{~m}$, com adubação na cova; $T_{3}$-cova de 0,30 x 0,30 x $0,30 \mathrm{~m}$, com adubação em cobertura; $\mathrm{T}_{4}$ - cova de $0,50 \times 0,50 \times 0,50 \mathrm{~m}$, com adubação na cova, e $\mathrm{T}_{5}-$ cova de $0,50 \times 0,50 \times 0,50 \mathrm{~m}$, com adubação em cobertura.

A variedade utilizada no experimento é uma seleção F2 da seleção do IAC275. Esse material faz parte do banco de germoplasma do programa de melhoramento genético do maracujazeiro da UFAC.

O plantio foi realizado no dia 23-11-2005, no espaçamento de 3,0 × 3,0 m, em espaldeira vertical, com um fio de arame a uma altura de $2 \mathrm{~m}$ do solo. Cada planta foi adubada com $10 \mathrm{~L}$ de composto orgânico, $6 \mathrm{~L}$ de cama de aviário e $200 \mathrm{~g}$ de termofosfato (Yoorin Master $^{\circledR}$ ). As covas foram abertas nas dimensões determinadas, e o adubo misturado com o próprio solo e retornado à cova. Nas covas com adubação em cobertura, após a abertura das mesmas e plantio, o adubo foi distribuído próximo à muda. Três meses após o plantio, aplicaram-se $20 \mathrm{~L}$ de cama de aviário por planta, em cobertura.

As mudas foram produzidas em sacos plásticos de polietileno preto com dimensões de $17,5 \mathrm{~cm}$ de comprimento por $7 \mathrm{~cm}$ de diâmetro, contendo substrato composto por casca de arroz carbonizada, terra de superfície e composto orgânico na proporção de 1:1:1, adicionados $10 \%$ de fino de carvão e $1,5 \mathrm{~kg}$ $\mathrm{m}^{-3}$ de termofosfato, e $1 \mathrm{~kg} \mathrm{~m}^{-3}$ de calcário dolomítico.

No primeiro ano, realizaram-se uma roçagem da braquiária para implantar a cultura e mais quatro capinas para implantar e estabelecer o amendoim forrageiro (Arachis pintoi) e o feijão-guandu (Cajanus cajan) nas entrelinhas de plantio. $\mathrm{O}$ amendoim foi roçado mais três vezes no segundo ano, e o feijão-guandu podado duas vezes.

Não foi preciso aplicar defensivos naturais, pois foi feita catação manual de lagartas (Agraulis vanilae e Dionae juno juno), enquanto a antracnose (Colletotrichum gloeosporioides) e a verrugose (Cladosporium herbarum) se mantiveram abaixo do dano econômico. Houve também uma planta que teve o caule danificado pela broca-da-haste (Philonis passiflorae)

As pequenas áreas para cultivo do maracujazeiro, de 0,45 a 0,75 ha, são recomendadas por proporcionarem os menores custos de produção (Agrianual, 2000); além disso, pelo tamanho dessas áreas, pode dispensar outro meio de controle de lagartasdo-maracujazeiro e utilizar apenas a catação manual. No entanto, em áreas maiores, o controle ecológico pode ser feito com produtos biológicos à base de Bacillus thuringiensis e Baculovírus) (Penteado, 2004).

Os frutos de cada parcela foram contados duas vezes por semana, e parte desses frutos pesados para obter o peso médio, que foi de $120 \mathrm{~g}$. Assim, a estimativa da produtividade ( $\mathrm{t}$ $\mathrm{ha}^{-1}$ ) foi calculada multiplicando o número de frutos pelo peso médio.

A colheita da primeira safra iniciou-se em maio de 2006, estendendo-se até agosto, e da segunda safra, de outubro de 2006 a junho de 2007. No Acre, o período de entressafra do maracujá ocorre pela estiagem das chuvas na região, pois a temperatura $\left(24,5^{\circ} \mathrm{C}\right)$ e a luminosidade $(>11 \mathrm{~h} /$ dia $)$ são suficientes para o florescimento constante da planta, desde que haja água disponível no solo. Neste caso, as plantas não foram irrigadas.

O custo de produção, conceituado como a soma de todos os valores (insumos) e operações (serviços) utilizados no processo produtivo de certa atividade, incluindo-se os respectivos custos alternativos ou de oportunidade, segue metodologias de custo e rentabilidade propostas por Reis (2002) e Vale \& Maciel (1998).

De acordo com esses autores, depreciação (D) é o custo necessário para substituir os bens de capital quando tornados inúteis, seja pelo desgaste físico, seja pelo econômico. No presente artigo, considerou-se apenas a depreciação da espaldeira, que dura, em média, 3 cultivos de 2,5 anos cada. $\mathrm{O}$ método utilizado foi o linear, referente a cada cultivo, que pode ser mensurado pela equação:

$$
D=\frac{V a-V r}{V u} P
$$

em que:

$\mathrm{D}$ - depreciação, R \$/cultivo;

$\mathrm{V}_{\mathrm{a}}$ - valor atual do recurso, $\mathrm{R} \$$

$\mathrm{V}_{\mathrm{r}}^{\mathrm{a}}$ - valor residual (o valor de revenda ou valor final do bem, após ser utilizado de forma racional na atividade), $\mathrm{R} \$$

$\mathrm{V}_{\mathrm{u}}$ - vida útil (período em ciclos que o bem é utilizado na atividade), e

$\mathrm{P}$ - período considerado, ciclo produtivo.

Para efeito da análise do custo de oportunidade dos recursos alocados na produção, considerou-se a taxa de juros de $12 \%$ a.a. Segundo Kuhner \& Bauer (1996), a taxa de juros ou taxa de atratividade a ser adotada no uso de técnicas destinadas à escolha entre várias alternativas de investimento consiste na taxa mínima de retorno que o investidor pretende conseguir como rendimento ao realizar algum investimento. De acordo com Leite (1998), a taxa de juros a ser escolhida para o cálculo do custo 
alternativo, deve ser igual à taxa de retorno da melhor aplicação alternativa; por ser impossível a determinação desse valor, optouse pela taxa selic, que é considerada a taxa básica de juros da economia, e refletir a lucratividade média das atividades produtivas da economia. No Brasil, em 2006 (ano de condução do experimento), a taxa de juros, aplicável na cobrança, restituição ou compensação dos tributos e contribuições federais, foi de aproximadamente $12 \%$ ao ano (Receita Federal, 2007).

A análise econômica consistiu de: custo de produção, análise econômica simplificada, receita líquida, ponto de nivelamento $\left(\mathrm{q}_{\mathrm{n}}\right)$ e ponto de resíduo $\left(\mathrm{q}_{\mathrm{r}}\right)$ (Reis, 2002; Araújo Neto, 2004). Nessa análise, podem-se encontrar diversas condições, dependendo da posição do preço em relação aos custos, e cada qual sugerindo uma interpretação particular, definida pelos indicadores econômicos obtidos. Este estudo apresenta-se ao fruticultor ecológico como um diagnóstico do comportamento econômico-financeiro de um ciclo da cultura (2 safras), com respeito à remuneração obtida, à cobertura dos recursos de curto (custos variáveis) e longo (custos fixos) prazos, à comparação entre a remuneração obtida pela atividade produtiva e aquela que seria proporcionada pelas outras alternativas de aplicação de recursos (Reis, 2002).

No Acre, não há entreposto de comercialização, os agricultores orgânicos e convencionais vendem direto aos feirantes e comerciantes, no atacado, em média a $R \$ 2,00 / \mathrm{kg}$, sendo vendidos no varejo acima de $R \$ 2,00 / \mathrm{kg}$, podendo alcança preços de até $\mathrm{R} \$ 4,50 / \mathrm{kg}$ ao consumidor. Por isso, neste trabalho, adotouse o preço de $\mathrm{R} \$ 1,50 / \mathrm{kg}$, caso haja um aumento da oferta e uma necessidade de venda rápida da fruta, garantindo maior confiabilidade das conclusões deste trabalho.

Apesar de o maracujá ter preço diferenciado pelo tamanho (classe), a nível nacional, ainda não se observa isso no Acre (observações pessoais) e por não ter sido possível obter a classificação da fruta nesta pesquisa, considerou-se um preço único da receita média $(\mathrm{RMe})$.

Os preços dos insumos foram levantados na região da localização do experimento, no período de novembro de 2005 a junho de 2007.

Considerou-se, para implantação da espaldeira, coveamento e limpeza da área, métodos manuais com auxílio de ferramentas, situação encontrada na região. $\mathrm{O}$ valor da diária de trabalho foi determinado tomano-se como base o maior valor pago na região: $\mathrm{R} \$ 20,00 / \mathrm{HD}$ (Homem-dia).

\section{Custo fixo}

$\mathrm{O}$ custo fixo corresponde à soma das contribuições dos fatores fixos ao produto total, em cada ciclo de produção; referese aos valores da depreciação, aluguel da terra, impostos fixos e juros sobre capital fixo.

Dessa forma, o custo de cada recurso fixo foi calculado somando-se seus correspondentes custos alternativos e o valor da depreciação, para cada ciclo de produção. Como recursos fixos, foram considerados a terra e o espaldeiramento.

A terra não se deprecia, com base no princípio da fruticultura orgânica, em que há um manejo de solo ecológico e, portanto, adequado, mantendo a terra sempre fértil, através das adubações, cobertura de solo, pousio e outras técnicas. O valor considerado é o seu custo alternativo, baseado no aluguel da terra explorada. $\mathrm{O}$ aluguel foi considerado como sendo de $\mathrm{R} \$ 100,00 / \mathrm{ha} / \mathrm{ano}$, valor pago no arrendamento de terras para pecuária no Acre, terras com características próprias à fruticultura, com disponibilidade de água, férteis e próximas aos centros urbanos.

\section{Custo variável}

Os recursos variáveis considerados e a forma de operacionalização dos custos correspondentes foram:

Mão-de-obra: corresponde ao custo do trabalho empregado em cada tratamento, inclusive com o manejo das leguminosas.

Insumos: correspondem ao gasto com aquisição de adubos, mudas e sementes de leguminosas e outros bens de produção que, ao entrarem no processo de produção, transformam-se, ou seja, não são observados no produto na sua forma original.

Comercialização: o custo com a comercialização é de grande importância na produção agrícola; neste caso, foi considerado o valor médio pago pelo transporte de uma carga média de $3.000 \mathrm{~kg}$, com custo de $\mathrm{R} \$ 150,00$, a uma distância média de $40 \mathrm{~km}$. Outro item da comercialização é a embalagem, feito com sacos de náilon.

A análise simplificada dos custos fornece parâmetros usados na mensuração da lucratividade do processo produtivo (Reis, 2002).

O lucro proveniente dos diferentes preparos do solo (coveamento) foi calculado pela diferença entre o valor da produção de 1,0 (um) hectare e o custo total médio por hectare, para um ciclo de produção de duas safras.

Ao se fazer a análise da atividade produtiva, pode-se deparar com diversas situações, dependendo da posição do preço em relação aos custos, cada qual sugerindo uma interpretação particular (Figura 1). Este estudo representa, para o produtor orgânico de maracujá, um diagnóstico do comportamento econômico-financeiro de um ciclo da cultura (duas safras), com respeito à remuneração obtida, à cobertura dos recursos de curto (custos variáveis) e longo (custos fixos) prazos, à comparação entre a remuneração obtida pela atividade produtiva e aquela que seria proporcionada pelas alternativas (custos alternativos) (Reis, 2002). Assim, os custos operacionais adotados (CopF, CopV) (Figura 1; Tabela 1) constituem-se nos custos com os insumos e serviços efetivamente empregados na atividade produtiva, excluídos os custos alternativos. E os custos médios (CopFMe e CopVMe) constituem-se nos valores do cociente dos custos fixos ou variáveis totais pela produtividade.

O ponto de nivelamento (qn), quantidade produzida cujo valor se iguala ao total de custos correspondente à sua produção (Vale \& Maciel, 1998), representa lucro normal, ou seja, receita bruta (RB) igual ao custo total (CT). Já o ponto de resíduo $\left(\mathrm{q}_{\mathrm{r}}\right)$ ocorre quando se obtém produto físico para o qual a receita bruta (RT) é igual aos custos operacionais totais $\left(\mathrm{C}_{\mathrm{op}} \mathrm{T}\right)$. Os pontos de nivelamento e de resíduo permitem avaliar a empresa quanto à possibilidade de otimizar a produção, considerando custos totais e operacionais, respectivamente. 
Os valores do ponto de nivelamento (qn) e de resíduo (qr) foram obtidos a partir das fórmulas:

$q n=\frac{C T}{\text { preço }}=\mathrm{kg} /$ ha/duas.safras $\quad q r=\frac{\text { CopT }}{\text { preço }}=\mathrm{kg} / \mathrm{ha} /$ duas safras

onde: $\mathrm{q}_{\mathrm{n}}$ - ponto de nivelamento; $\mathrm{CT}$ - custo total; $\mathrm{q}_{\mathrm{r}}-$ ponto de resíduo; $\mathrm{C}_{\mathrm{op}} \mathrm{T}$ - custo operacional total.

O índice de rentabilidade (IR) foi calculado mediante a razão entre a receita bruta e o custo operacional total $\left(\mathrm{C}_{\mathrm{op}} \mathrm{T}\right)$.

Os coeficientes técnicos referentes às operações de preparo do solo, implantação e condução da cultura foram determinados através do acompanhamento dos experimentos.

Os dados de produção e os econômicos foram testados em análise de variância por meio do teste F, e as médias, comparadas pelo teste de Tukey, ambos a 5\% de probabilidade.

\section{RESULTADOS E DISCUSSÃO}

Houve efeito do sistema de plantio sobre todas as características analisadas (Tabelas 1 e 2).

Em todos os tratamentos, observou-se lucro supernormal ( $\mathrm{CTMe}<\mathrm{RMe}$ ), com custos totais médios e operacionais médios maiores para os sistemas com plantio em covas de $0,50 \mathrm{~m}$, por apresentarem custos maiores (Tabela 3 ) e produtividades menores (Tabela 2) que os dos outros tratamentos, fatores que contribuem para a elevação dos custos médios.

Nessa situação de lucro supernormal, que paga todos os recursos aplicados na atividade econômica e proporciona um lucro adicional, superior ao de outras alternativas de mercado, a tendência é que outros agricultores entrem na atividade. Essa presumível tendência é incompatível com o cenário da cultura do maracujá no Brasil, caracterizado por preços baixos e abandono de áreas (Meirelles, 2006). Mas esse lucro foi proporcionado pelo alto preço considerado ( $\mathrm{R} \$ 1,50 / \mathrm{kg}$ ), bem acima do preço histórico praticado nacionalmente pela indústria (Guedes \& Vilela, 1999) e pelo mercado de maracujá in natura de $\mathrm{R} \$ 0,35 / \mathrm{kg}$ a $\mathrm{R} \$ 0,62 /$ $\mathrm{kg}$, comercializados nas ceasas do DF e SP, e em BH (Agrianual, 2007). A importância do alto preço pago no mercado local, em relação à situação de lucro supernormal, fica mais evidente quando se verifica que a produtividade foi praticamente $62 \%$ menor que a produtividade nacional, de 13,4 t/ha/ano, e $40 \%$ menor que a produtividade acreana, de 8,4 t/ha/ano (Agrianual, 2007).

Essa baixa produtividade, nos dois casos, é causada em grande parte pela deficiência de polinização, um dos principais problemas do maracujá na região, decorrente da baixa população de abelhas polinizadoras (mamangavas) e efeito negativo dos fatores abióticos (estiagem prolongada, precipitação pluviométrica excessiva na floração, solos com baixa fertilidade natural) e fatores bióticos (presença de abelhas silvestres e exóticas).

A receita líquida foi maior nos sistemas de preparo com covas de $0,30 \mathrm{~m}$ - com adubação na cova ( $\mathrm{R} \$ 10.234,19 / \mathrm{ha})$ e em cobertura ( $\mathrm{R} \$ 11.501,44 / \mathrm{ha})$ - e no plantio direto $(\mathrm{R} \$ 8.925,08 / \mathrm{ha})$
(Tabela 2); estes resultados contrariam a situação atual da produção de maracujá no Brasil, que a baixa rentabilidade da cultura levou a forte retração (Meireles, 2006). Esta receita líquida favorável ao agricultor foi fortemente influenciada pelo preço da fruta e pelos baixos custos decorrentes da não-utilização de insumos externos, como fertilizantes e agrotóxicos, insumos que oneram significativamente a produção de maracujazeiro. Analisando-se os custos de produção desta fruta, os insumos fitossanitários são os principais responsáveis pelo aumento do custo, que representa de 11 a 12,5\% do custo total, sem contar os gastos com fertilizantes, que representam de 4,2 a 5,2\% do custo total (Silva et al., 2003; Agrianual, 2007).

A produtividade das duas safras deste experimento foi de $10,2 \mathrm{t} /$ ha, abaixo da produtividade da região para duas safras $(16,8 \mathrm{t} / \mathrm{ha})$.

O preço do maracujá local é alto, principalmente pela baixa produção regional, sendo que a maior parte da produção consumida é importada das outras regiões brasileiras. Numa situação de lucro supernormal, muitos agricultores devem entrar no mercado e, conseqüentemente, o preço da fruta deve cair, exigindo aumentos de produtividade. Para aumentar a produtividade do maracujá, pode-se utilizar polinização artificial (Camillo, 2003), maior quantidade de adubo orgânico, aplicação de calda sulfocálcica, biofertilizantes (Penteado, 2004), variedades melhoradas para as condições locais (Oliveira et al., 1998), entre outras alternativas tecnológicas.

O custo total de produção deste experimento ( $\mathrm{R} \$ 7.985,73 /$ ha a $\mathrm{R} \$ 8.368,11$ ha nas duas safras) (Tabela 3 ) ficou bem abaixo do custo de produção do maracujá em sistema convencional de alta produtividade (R $\$ 20.502,00 / \mathrm{ha} / 2$ anos) (Agrianual, 2007) e de baixa produtividade ( $\mathrm{R} \$ 10.438,56 / \mathrm{ha} / 2$ safras) (Araújo Neto, 2004), contribuindo para isso a ausência de polinização manual, o curto período de colheita e a não-aplicação de fertilizantes químicos e agroquímicos.

Um dos princípios da agricultura sustentável é reduzir o uso de matéria e energia, de forma a manter alto o balanço energético na produção, ou seja, gastar o mínimo de energia no processo produtivo (Souza \& Resende, 2006); e não apenas substituir insumos sintéticos por insumos naturais (Canuto, 2004), mas aplicar processos de adubação verde, proteção do solo, plantas companheiras, aproveitamento de luz, mantendo a produtividade acima do ponto de nivelamento (Tabela 2), garantindo a conservação dos recursos naturais e a remuneração justa ao agricultor, proposta pela Lei 10.831, de 23 de dezembro de 2003 (Brasil, 2003) e estabelecido na Agenda 21 brasileira.

O que mais onerou os custos de produção foi o uso de mão-de-obra, variando de $34 \%$ no plantio direto a $40 \%$ no sistema de covas de $50 \mathrm{~cm}$ com adubação na cova (Tabela 3). Essa mãode-obra foi utilizada principalmente nas operações de plantio do maracujá e manutenção das plantas de cobertura.

A mão-de-obra corresponde à contratação de 112 diárias, o equivalente a 0,12 emprego por hectare, bem abaixo da necessidade de mão-de-obra para a cultura convencional, que varia de 0,24 emprego/ha (Araújo Neto, 2004) a 0,69 emprego/ha (Agrianual, 2007).

O uso de amendoim forrageiro cobrindo o solo, além da 
fixação biológica de nitrogênio, diminui a necessidade de capina. O fato de não se utilizar polinização artificial e o curto período de colheita são os fatores responsáveis pela pouca utilização de mão-de-obra. Esse fato, torna a cultura do maracujazeiro importante estratégia para as famílias agroecológicas do Acre. Além disso, os menores custos de produção verificam-se nos extratos de produtores que cultivam áreas entre 0,45 e 0,75 ha (Agrianual, 2000).

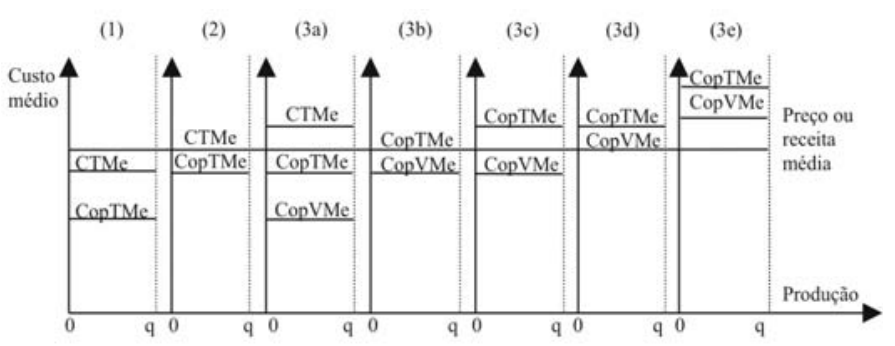

CTMe-custo total médio; CopTMe-custo operacional total médio; CopVMe - custo operacional variável médio; (1) - lucro super-normal (RMe>CTMe); (2) - lucro normal (RMe=CTMe); (3a) - resíduo positivo (CTMe $>\mathrm{RMe}>\mathrm{CopTMe})$; (3b) - resíduo nulo (RMe = CopTMe); (3c) - resíduo nulo com cobertura dos custos variáveis e de parte do custo fixo (CopTMe $>\mathrm{RMe}>\mathrm{CopVMe}) .(3 \mathrm{~d})$ resíduo negativo sem cobertura dos recursos fixos $(\mathrm{Rme}=\mathrm{CopVme})$ e somente parte dos recursos variáveis; (3e) resíduo negativo, sem cobrir os recursos variáveis ou capital de giro (Rme $<$ CopeVMe).

FIGURA 1- Situações de análises econômica e operacional de uma atividade produtiva. Fonte: Reis (2002).

TABELA 1 - Custos econômicos e operacionais médios da produção do maracujazeiro-amarelo em 2 safras, nos diferentes tipos de preparo do solo. Rio Branco - AC, UFAC, 2007*.

\begin{tabular}{|c|c|c|c|c|c|c|}
\hline Tratamentos & $\underline{\text { CFM }}$ & $\begin{array}{l}\text { CVMe } \\
\text { (R\$/kg) }\end{array}$ & TMe & Cop & $\frac{\text { CopVM }}{(\mathrm{R} \$ / \mathrm{kg}}$ & TMe \\
\hline Plantio direto + Adub ação em cobertura & $0,23 \mathrm{bc}$ & $0,52 \mathrm{bc}$ & $0,75 \mathrm{bc}$ & $0,19 \mathrm{bc}$ & $0,40 \mathrm{bc}$ & $0,59 \mathrm{bc}$ \\
\hline Cova de $30 \times 30 \times 30+$ Adubação na cova & $0,20 \mathrm{c}$ & $0,48 \mathrm{bc}$ & $0,68 \mathrm{bc}$ & $0,16 \mathrm{bc}$ & $0,36 \mathrm{c}$ & $0,52 \mathrm{c}$ \\
\hline Cova de $30 \times 30 \times 30$ + Adubação em cobertura & $0,19 \mathrm{c}$ & $0,45 \mathrm{c}$ & $0,64 \mathrm{c}$ & $0,15 \mathrm{c}$ & $0,34 \mathrm{c}$ & $0,49 \mathrm{c}$ \\
\hline Cova de $50 \times 50 \times 50+$ Adub ação na cova & 0,41 a & $0,97 \mathrm{a}$ & 1,38 a & 0,34 a & $0,80 \mathrm{a}$ & 1,14 a \\
\hline Cova de $50 \times 50 \times 50+$ Adubação em cobertura & $0,38 \mathrm{ab}$ & $0,87 \mathrm{ab}$ & $1,25 \mathrm{ab}$ & $0,30 \mathrm{ab}$ & $0,71 \mathrm{ab}$ & $1,01 \mathrm{ab}$ \\
\hline Média & 0,28 & 0,66 & 0,94 & 0,23 & 0,52 & 0,75 \\
\hline C.V. $(\%)$ & 12,06 & 12,59 & 12,56 & 12,43 & 12,65 & 12,53 \\
\hline
\end{tabular}

* Médias seguidas de letras distintas não diferem entre si pelo teste de Tukey à $5 \%$ de probabilidade.

*CFMe - custo fixo médio; CVMe - custo variável médio; CTMe - custo total médio; CopFMe - custo operacional fixo médio; CopVMe - custo operacional variável médio; CopTMe - custo operacional total médio.

TABELA 2 - Rentabilidade econômica, índice de rentabilidade e ponto de nivelamento em 2 safras, nos diferentes tipos de preparo do solo. Rio Branco - AC, UFAC, 2007*

\begin{tabular}{|c|c|c|c|c|c|}
\hline Tratamentos & $\begin{array}{c}\mathbf{R L} \\
(\mathrm{R} \$ / \mathrm{ha} / 2 \mathrm{anos}) \\
\end{array}$ & IR & $\begin{array}{c}\mathbf{q n} \\
(\mathrm{kg} / \mathrm{ha})\end{array}$ & $\begin{array}{c}\mathbf{q r} \\
(\mathrm{kg} / \mathrm{ha})\end{array}$ & $\begin{array}{l}\text { Produtividade } \\
\left(\mathrm{kg} \mathrm{ha}^{-1} 2 \mathrm{anos}^{-1}\right)\end{array}$ \\
\hline Plantio direto + Adubação em cobertura & $8.925,08 \mathrm{ab}$ & $2,7 \mathrm{a}$ & 5.324 & 4.154 & $10.928,3 \mathrm{ab}$ \\
\hline Cova de $30 \times 30 \times 30+$ Adubação na cova & $10.234,19$ a & $2,9 \mathrm{a}$ & 5.579 & 4.321 & $11.554,5 \mathrm{ab}$ \\
\hline Cova de $30 \times 30 \times 30$ +Adubação em cobertura & $11.501,44 \mathrm{a}$ & $3,1 \mathrm{a}$ & 5.462 & 4.198 & $12.165,8 \mathrm{a}$ \\
\hline Cova de 50x50x50 + Adubação na cova & $1.252,56 \mathrm{c}$ & $1,4 \mathrm{~b}$ & 5.452 & 4.471 & $8.354,5 \mathrm{ab}$ \\
\hline Cova de $50 \times 50 \times 50+$ Adubação em cobertura & $2.636,50 \mathrm{cb}$ & $1,7 \mathrm{~b}$ & 5.485 & 4.459 & $7.850,8 \mathrm{~b}$ \\
\hline Média & $6.909,95$ & 2,3 & - & - & $10.170,8$ \\
\hline $\begin{array}{ll}\text { C.V. }(\%) \\
\end{array}$ & 20,04 & 10,49 & - & - & 9,67 \\
\hline
\end{tabular}

* Médias seguidas de letras distintas não diferem entre si, pelo teste de Tukey, a 5\% de probabilidade.

* $\mathrm{RL}$ - receita líquida; IR - índice de rentabilidade, $\mathrm{q}_{\mathrm{n}}$ - Ponto de nivelamento; qr - ponto de resíduo.

TABELA 3 - Estimativa de custo para 1 ha da cultura do maracujazeiro-amarelo em 2 safras, nos diferentes tipos de preparo do solo. Rio Branco -AC, UFAC, 2007

\begin{tabular}{|c|c|c|c|c|c|c|c|c|c|c|}
\hline \multirow{2}{*}{$\begin{array}{l}\text { Custos fixos e } \\
\text { Variáveis } \\
\text { Custos Fixos }\end{array}$} & \multicolumn{2}{|c|}{ Plantio direto } & \multicolumn{2}{|c|}{$\begin{array}{l}\text { Covas de } 0,30+ \\
\text { Adub. na cova }\end{array}$} & \multicolumn{2}{|c|}{$\begin{array}{c}\text { Covas de 0,30 + } \\
\text { Adub. Cobertura } \\
\end{array}$} & \multicolumn{2}{|c|}{$\begin{array}{c}\text { Covas de } 0,50+\text { Adub. } \\
\text { na cova }\end{array}$} & \multicolumn{2}{|c|}{$\begin{array}{c}\text { Covas de 0,50 + } \\
\text { Adub. cobertura } \\
\end{array}$} \\
\hline & (\%) & $\mathrm{R} \$$ & $(\%)$ & $\mathrm{R} \$$ & $(\%)$ & $\mathrm{R} \$$ & $(\%)$ & $\mathrm{R} \$$ & $(\%)$ & $\mathrm{R} \$$ \\
\hline Terra & 2,50 & 200,00 & 2,39 & 200,00 & 2,44 & 200,00 & 2,45 & 200,00 & 2,43 & 200,00 \\
\hline Espaldeiramento & 24,89 & $1.988,00$ & 23,76 & $1.988,00$ & 24,27 & $1.988,00$ & 24,31 & $1.988,00$ & 24,16 & $1.988,00$ \\
\hline ITR & 0,004 & 0,28 & 0,003 & 0,28 & 0,003 & 0,28 & 0,003 & 0,28 & 0,003 & 0,28 \\
\hline Custo alternativo & 3,288 & 262,59 & 3,138 & 262,59 & 3,205 & 262,59 & 3,211 & 262,59 & 3,192 & 262,59 \\
\hline CFT & 30,69 & $2.450,87$ & 29,29 & $2.450,87$ & 29,92 & $2.450,87$ & 29,97 & $2.450,87$ & 29,79 & $2.450,87$ \\
\hline \multicolumn{11}{|l|}{ Custos variáveis } \\
\hline Insumos & 19,27 & $1.539,00$ & 18,94 & $1.585,00$ & 19,27 & $1.579,00$ & 17,71 & $1.448,00$ & 17,87 & $1.470,00$ \\
\hline Mão-de-obra & 33,86 & $2.704,00$ & 34,75 & $2.908,00$ & 33,32 & $2.730,00$ & 39,99 & $3.270,00$ & 39,26 & $3.230,00$ \\
\hline Comercialização & 9,80 & 782,70 & 10,58 & 885,08 & 11,17 & 915,47 & 5,41 & 442,33 & 6,22 & 512,12 \\
\hline Custo alternativo & 6,38 & 509,16 & 6,44 & 539,16 & 6,31 & 517,08 & 6,92 & 566,16 & 6,86 & 564,00 \\
\hline CVT & 69,31 & $5.534,86$ & 70,71 & $5.917,24$ & 70,08 & $5.741,55$ & 70,03 & $5.726,49$ & 70,21 & $5.776,12$ \\
\hline CT $(\mathrm{CFT}+\mathrm{CVT})$ & 100,00 & $\mathbf{7 . 9 8 5 , 7 3}$ & 100,00 & $8.368,11$ & 100,00 & $8.192,42$ & 100,00 & $8.177,36$ & 100,00 & $8.226,99$ \\
\hline
\end{tabular}




\section{CONCLUSÕES}

1-O cultivo orgânico de maracujá, utilizando covas cúbicas com $0,30 \mathrm{~m}$ de lado ou plantio direto da muda, proporciona maiores rendimentos econômicos e custos de produção menores que o plantio em covas cúbicas de $0,50 \mathrm{~m}$ de lado.

2- Em decorrência dos índices de rentabilidade obtidos e do maior potencial produtivo da cultura, tem-se no maracujáamarelo uma boa opção de plantio pela agricultura familiar e ecológica do Acre.

\section{REFERÊNCIAS}

AGRIANUAL 2000: anuário da agricultura brasileira. São Paulo: FNP Consultoria, 2000. p. 398.

AGRIANUAL 2007: anuário da agricultura brasileira. São Paulo: FNP Consultoria, 2007. p. 387-395.

ARAÚJO NETO, S. E. de. Produção, qualidade e rentabilidade do maracujazeiro-amarelo em diferentes densidades de plantio. 2004. 72 f. Tese (Doutorado em Agronomia - Fitotecnia) Universidade Federal de Lavras, Lavras, 2004.

BRASIL. Lei 10.831 de 23 de dezembro de 2003. Dispõe sobre normas para a produção de produtos orgânicos vegetais e animais. Disponível em <www.planetaorgânico.com.br>. Acesso em 29 mar. 2006.

CANUTO, J. C. Dimensão socioambiental da agricultura sustentável. In: UZÊDA, M. C. (Org.) O desafio da agricultura sustentável: alternativas viáveis para o sul da Bahia. Ilhéus-BA: Editus, 2004. p.13-32.

CAMILLO, E. Polinização do maracujá. Ribeirão Preto: Holo, 2003. 44 p.

CAVALCANTI, C. Uma tentativa de caracterização da economia ecológica. Ambiente \& Sociedade, Campinas, v. 7, p.149-158, jan./jun. 2004.

GUEDES, L. de O.; VILELA, P. S. O mercado do maracujá. Belo Horizonte: FAEMIG, Infoagro, 1999. 16 p. (Série Fruticultura).

KUHNER, O. L.; BAUER, U. R. Matemática financeira aplicada à análise de investimento. 2.ed. São Paulo: Atlas, 1996. 517 p.
LEITE, C.A.M. Planejamento da empresa rural. Brasília: 1998. v.4, 66p. Curso de Especialização por Tutoria a Distância.

MEIRELLES, M. C. Maracujá maravilha. Frutas e Derivados, São Paulo, v. 1, n.4, p.31-33, Dez.2006.

OLIVEIRA, J. C.; RUGGIERO, C. Aspecto sobre o melhoramento do maracujazeiro-amarelo. In: SIMPÓSIO BRASILEIRO SOBRE A CULTURA DO MARACUJAZEIRO, 5., 1998, Jaboticabal. Anais... Jaboticabal: FUNEP, 1998. p. 291-310.

NASCIMENTO, A. V. S.; SOUZA, A. R. R.; ALFENAS, P. F.; ANDRADE, G. P.I; CARVALHO, M. G.; PIO-RIBEIRO, G.; ZERBINI, F. M. Análise filogenética de potyvírus causando endurecimento dos frutos do maracujazeiro no Nordeste do Brasil. Fitopatologia Brasileira, Brasília, v.29, n 4, p.378-383, 2004.

PENTEADO, S. R. Fruticultura orgânica: formação e condução. Viçosa: Aprenda Fácil, 2004. 308 p.

RECEITA FEDERAL. Taxa selic. Disponível em: <http:// w w w . r e c e i t a g o v . b r / P a g a m e n to s/ jrselic.htm\#Taxa_de_Juros_Selic>.Acesso em: 23 ago. 2007.

REIS, R. P. Fundaments de economia aplicada. Lavras: UFLA/ FAEPE, 2002. 95 p. Texto Acadêmico

SIMÃO, S. Manual de fruticultura. São Paulo: Agronômica Ceres, $1971.530 \mathrm{p}$.

SILVA, A. V. C. da; ANDRIAZZI, C. V. G.; CAPUTO, M. M.; SEVALI, P. L. Custos de produção. In: TODAFRUTA. Maracujá. Disponível em: <www.todafruta.com.br/>. Acesso em: 27 nov. 2003.

SILVA, J. R. da; OLIVEIRA, H. J. de. Implantação da cultura, manejo e tratos culturais. In: BRUCKNER, C. H.; PICANÇO, M. C. Maracujá: tecnologia de produção, pós-colheita, agroindústria, mercado. Porto Alegre: Cinco continentes, 2001. p.139-162.

SOUZA, J. L. de; RESENDE, P. Manual de horticultura orgânica. Viçosa: Aprenda Fácil Editora, 2006. 823 p.

SOUZA, J. L. de. Agricultura orgânica: tecnologia para produção de alimentos saudáveis. Vitória, ES: Incaper, 2005. 2v, 257 p.

VALE, S. M.; MACIEL, M. Administração rural. Brasília: 1998. v.2, 66 p. Curso de Especialização por Tutoria a Distância. 